\title{
SOCIAL SECURITY HEALTH INSURANCE FOR THE INFORMAL SECTOR IN NICARAGUA: A RANDOMIZED EVALUATION
}

\author{
REBECCA L. THORNTON ${ }^{\mathrm{a}, *}$, LAUREL E. HATT ${ }^{\mathrm{b}}$, ERICA M. FIELD ${ }^{\mathrm{c}}$, MURSALEENA ISLAM $^{\mathrm{b}}$, \\ FREDDY SOLÍS DIAZ ${ }^{\mathrm{d}}$ and MARTHA AZUCENA GONZÁLEZ \\ ${ }^{\mathrm{a}}$ University of Michigan, Economics, Ann Arbor, MI, USA \\ ${ }^{\mathrm{b}}$ PSP-One Project, Abt Associates Inc., Washington, DC, USA \\ ${ }^{\mathrm{c}}$ Harvard University, Economics, Cambridge, MA, USA \\ d ALVA Consultores, Managua, Nicaragua
}

\begin{abstract}
SUMMARY
This article presents the results from an experimental evaluation of a voluntary health insurance program for informal sector workers in Nicaragua. Costs of the premiums as well as enrollment location were randomly allocated. Overall, take-up of the program was low, with only $20 \%$ enrollment. Program costs and streamlined bureaucratic procedures were important determinants of enrollment. Participation of local microfinance institutions had a slight negative effect on enrollment. One year later, those who received insurance substituted toward services at covered facilities and total out-of-pocket expenditures fell. However, total expenditures fell by less than the insurance premiums. We find no evidence of an increase in health-care utilization among the newly insured. We also find very low retention rates after the expiration of the subsidy, with less than $10 \%$ of enrollees still enrolled after one year. To shed light on the findings from the experimental results, we present qualitative evidence of institutional and contextual factors that limited the success of this program. Copyright (C) 2010 John Wiley \& Sons, Ltd.
\end{abstract}

Received 21 April 2009; Revised 20 May 2010; Accepted 25 May 2010

KEY WORDS: health insurance; randomized experiment; Nicaragua; microfinance institutions

\section{INTRODUCTION}

In recent years, interest has grown in providing health insurance programs to poor and vulnerable populations throughout the world as a means of increasing access to priority health services and protecting families from catastrophic health-care costs. ${ }^{1}$ Implementation of such programs, however, may be difficult. Research suggests that take-up of voluntary health insurance among the poor is typically low (Behrman and Knowles, 1999; Jowett, 2003; Morduch, 1999; Chankova et al., 2008; Gine et al., 2007; Alderman and Paxson, 1994; Fafchamps, 1999; Pauly et al., 2008). Moreover, collecting payments from this population, who are generally employed in the informal sector, is challenging (AbelSmith, 1992). Finally, if the program is not carefully designed and marketed, insurance schemes targeted to the poor may be particularly prone to adverse selection, disproportionately attracting those who are relatively sick.

\footnotetext{
*Correspondence to: Department of Economics, 611 Tappan St., Ann Arbor, MI 48109, USA. E-mail: rebeccal@umich.edu

${ }^{1}$ There are a growing number of health insurance programs and academic evaluations of these programs in developing countries. See, for example, Abel-Smith (1992); Barros (2009); Dow and Schmeer (2003); Duflo et al. (2004); Gakidou et al. (2006); Gertler and Gruber (2002); Gertler and Solon (2002); GTZ et al. (2005); King et al. (2009); Kremer et al. (2006); Miller et al. (2009); Panopoulus and Vélez (2001): Pauly et al. (2006); Pauly et al. (2008); Wagstaff (2007). See also Dercon et al. (2008).
} 
Despite the recent and increasing interest in health insurance programs for excluded populations in developing countries (Preker et al., 2002; Gumber and Kulkarni, 2000; Franco et al., 2008; Smith and Sulzbach, 2008), there is little rigorous evidence on the optimal design of voluntary health insurance schemes targeting the informal sector in terms of their ability to attract a large enough pool of individuals or to increase utilization of quality health services. For instance, in many developing countries, existing synergies between the delivery of financial services and health services to clients in the informal sector have led policy-makers to believe that microfinance institutions (MFIs) may be a promising delivery agent to extend health insurance to low-income and other vulnerable groups (Matin et al., 2002; Churchill, 2003; Churchill and Cohen, 2006), particularly in settings where MFI penetration is high. Despite this belief, however, to date no evidence supports the utility of using MFIs in marketing and delivering insurance products.

In addition to the lack of evidence of the effects of alternative insurance schemes and delivery, there is also a dearth of evidence on the effects of voluntary insurance among the poor on utilization, expenditures, and health. This may be largely in part due to the difficulty in making causal inferences from cross-sectional or panel studies. Nonexperimental studies that aim to measure the impact of voluntary health insurance coverage are prone to omitted variable bias. For instance, if those who are more likely to be sick or utilize health services are more likely to purchase health insurance, unobservable differences between the insured and the uninsured will confound estimates of the effect of insurance, although the direction of the bias is ambiguous.

This article evaluates a voluntary public health insurance program targeted to informal sector workers in Nicaragua and provides experimental evidence on the determinants of enrollment, as well as the causal effects of insurance on health-care expenditures, outcomes, and patterns of utilization among informal sector workers. In January 2007, the government of Nicaragua initiated a demonstration project that extended the Nicaraguan Social Security Institute's (INSS's) health insurance program for formal sector employees to informal sector workers using MFIs as delivery agents.

To evaluate the impact of the program, we randomly varied the costs and convenience of enrolling in the new health insurance program across a large sample of market vendors in Managua. To study the effectiveness of MFIs as delivery agents, we randomly assigned individuals to purchase the insurance at either the INSS central office or the branch offices of three participating MFIs. We then used baseline and follow-up surveys to examine changes in health and health-care utilization.

Differences in take-up rates across treatment arms provide evidence on the extent to which the financial cost and the convenience of enrollment procedures influence enrollment and retention in the insurance program, as well as the effectiveness of MFIs as health insurance delivery agents. In turn, variation in take-up by treatment assignment generates random variation in insurance coverage, allowing us to measure the effects of the insurance using baseline and follow-up surveys conducted one year apart. In addition to the quantitative analysis of the demand for and effects of health insurance, we also conducted a series of focus groups and in-depth interviews to better understand take-up of the insurance program, retention, and utilization of health services.

We find that while insured individuals switched from using services at private and Ministry of Health facilities to visiting covered health facilities, insurance coverage did not appear to substantially increase their overall utilization of services. Meanwhile, although total out-of-pocket (OOP) expenditures fell when individuals were insured, average OOP savings were lower than the equivalent unsubsidized insurance premiums. More fundamentally, we find very low take-up and retention rates, with only $20 \%$ enrolling at baseline and fewer than $10 \%$ of those enrollees still enrolled in the insurance program after one year. While there are various possible explanations for the failure of the program to attract and retain clients, the finding is consistent with case studies from developing countries, which suggest that, in settings in which individuals have lower levels of discretionary income, insurance is often perceived as a net gain only for those with health-care costs above the price of insurance. Nonetheless, $11 \%$ of 
respondents who did not enroll had higher baseline health expenditures for themselves and children under 12 than the cost of the annual premium, which suggests that uncertainty, lack of information, or distrust of the insurance product may have also played a role in reducing demand for coverage.

There was a slight negative effect (5.4 percentage points) on enrollment among those assigned to the MFIs, suggesting that in this instance, MFIs were not a more effective health insurance delivery agent than the government. Qualitative data point to a number of obstacles in working with MFIs that must be addressed before similar strategies are successful, including bureaucratic and administrative challenges and those related to promotion and marketing. ${ }^{2}$

The findings from Nicaragua provide valuable evidence for other developing countries interested in expanding public health insurance programs to the informal sector. Although the insurance product considered in this evaluation has several context-specific design features that may affect the generalizability of our findings, the program in Nicaragua is in most ways a very typical government health insurance scheme, comparable to public sector programs for formal sector workers in many parts of the world. Hence, our study provides useful evidence on the efficacy of extending existing public insurance programs in many developing countries to the informal sector. Such an approach has the potential to be particularly cost effective since governments already have a broad risk pool of mandatory insured workers and higher volumes may reduce the overall cost of service delivery. Similarly, although this program was not designed to reach the ultrapoor (for instance, by requiring nontrivial premiums and a fair amount of paperwork), it is a logical first step for a government interested in extending its existing program to the self-employed.

The article proceeds as follows: Section 2 presents the background and program description for the health insurance product in Nicaragua. Section 3 presents the quantitative methodology and empirical strategy, and Section 4 discusses the quantitative results of the evaluation. Section 5 discusses contextual findings and qualitative results, and Section 6 concludes.

\section{BACKGROUND AND PROGRAM DESCRIPTION}

Latin America has the highest proportion of countries in which private health insurance contributes over 5\% to total health expenditure (Laver, 2000) and there has been a great focus on reforms and provision of health services in many of these countries. In Nicaragua, private insurance accounts for only $2.1 \%$ of total health expenditure (and $4 \%$ of private health expenditure). OOP payments as a percentage of total health expenditure is large $(47.9 \%)$ and makes up almost all $(93.1 \%)$ of private health expenditures (Sekhri and Savedoff, 2005). Increasing access to health insurance in Nicaragua may help to mitigate the OOP costs.

Before the expansion of health insurance to informal sector workers in January 2007, only formal sector workers and government employees in Nicaragua were eligible for INSS health insurance and health services provided at 17 INSS-contracted facilities. This participation represented just $18.5 \%$ of

\footnotetext{
${ }^{2}$ Perhaps the most similar study to this one is a recent evaluation by King et al. (2009), where the authors evaluated a health insurance program in Mexico that randomized encouragement to sign up for insurance across health facilities. Similar to our study, they measured the shorter term effects (after 10 months) and found a reduction in health expenditures; there were no effects on health outcomes or overall utilization (King et al., 2007, 2009). Another study similar to ours evaluated the expansion of government health insurance to the informal sector in Mexico in 2002 (Barros, 2009). Barros found, as we did, a substitution of visits to service providers and a reduction in out of pocket expenditures. See also Wang et al. (2009). Other studies have evaluated the effects of health insurance in Columbia and have also found increased utilization and reduced out-of pocket expenditure (Giedion et al., 2007). Our study differs from these and others in two main ways. First, we evaluate a randomized experiment that allows for causal inference for a variety of research questions without the usual concerns of selection bias or endogenous program take-up. Second, our quantitative results are complemented with in-depth qualitative research that explores the influence of contextual factors on both take-up rates and efficacy of the insurance program in Nicaragua.
} 
the economically active population in Nicaragua. Individuals working in the informal sector, the selfemployed, and the unemployed were eligible only for care at a handful of Ministry of Health (MINSA) facilities, which were under-resourced and lacked the infrastructure, staff, and medications needed to respond adequately to the population's health needs. Focus groups with informal sector workers conducted in 2006 revealed that they perceived MINSA facilities as offering significantly lower quality of care than INSS-contracted facilities and other private health providers, including very long wait times and stock-outs (Magnoni et al., 2005). As a result, workers reported that they tended to avoid MINSA facilities and instead generally went directly to pharmacies for basic care. In other cases, they preferred paying private doctors or avoiding care altogether, incurring the risk of more extensive (and expensive) procedures down the line. ${ }^{3}$

Microentrepreneurs in Nicaragua, as in many parts of the developing world, are vulnerable to family health crises in terms of their impacts on household income and business cash flows (Dercon, 2002). They typically divert resources from their businesses to meet immediate health-care needs at the expense of investing in their business and its future growth, which in turn can have a significant impact on future household income (McIntyre et al., 2006; Morduch and Sharma, 2002; Narayan et al., 2000; Russell, 2004). In these cases, therefore, health insurance serves to reduce financial risk for small businesses, as well as for informal workers and their families.

The health insurance provided through the Nicaraguan government's social security system (INSS) extends care to formal sector workers based on mandatory payroll and employer contributions. INSS contracts with commercial, not-for-profit, and public providers (formerly Empresas Médicas Previsionales and referred to in this article as EMPs), purchasing services on a capitated basis. The INSS insurance provides all subscribers with a comprehensive package of preventive, diagnostic, and curative health services, including primary and specialist care, medication and laboratory exams, hospitalization, 24-hour emergency care, prenatal care, childbirth and postnatal care, infant care and vaccinations, child wellness visits through age 5, pediatric care through age 11, voluntary family planning counseling and contraception, breast and cervical cancer screenings, HIV and STD counseling, and prevention and treatment of dengue fever and malaria. In addition to the subscriber, the subscriber's wife is eligible for maternity services, including deliveries, and dependent children up to the age of 12 are also fully covered.

In 2007, a parallel version of this health insurance was made available to informal sector workers through a voluntary mechanism known as Seguro Facultativo de Salud. Although the program for this sector was voluntary, the coverage and cost were designed to be as similar as possible to those associated with the program for workers employed in the formal sector. In this program, individuals had the opportunity to pay a flat monthly fee for a wide range of covered services without copayment at the time of service. The cost of the program was structured such that the monthly fee was higher in the first two months, at approximately 18 dollars per month, and then fell to approximately 15 dollars per month in subsequent months. When subscribers unenrolled, they would continue to be covered during a 3-month grace. Enrolled individuals could make monthly payments directly at the INSS office or through most banks in the country.

Given the high rate of MFI use among informal sector workers in Nicaragua, policymakers hypothesized that it would be convenient for these workers to enroll and make health insurance payments at MFIs, perhaps concomitant with making payments on MFI loans. ${ }^{4}$ The government contracted three MFIs to market the new insurance scheme and collect premiums: ACODEP, Banco ProCredit, and Findesa. Each MFI received technical assistance with management information systems,

\footnotetext{
${ }^{3}$ Other research also indicated widespread dissatisfaction with the quality of services, although there have been attempts at reforming the health system (Jack, 2003).

${ }^{4}$ In Nicaragua, there are over 200 MFIs with over 20 that cover the majority of the unbanked market, offering a variety for public-private partnerships in health insurance delivery.
} 
operations, enrollment procedures, and marketing health insurance to informal workers. ${ }^{5}$ The MFIs signed a one-year contract with INSS in October 2006 for registering subscribers and collecting payments in exchange for which they received a small fee for each enrolled worker.

Over the course of the evaluation, a number of institutional and political changes took place that influenced project implementation. Importantly, the MFI partnerships were established under the government of Enrique Bolaños, who was replaced in January 2007 by incoming President Daniel Ortega - representing an administration with a radically different political ideology. In October 2007, INSS chose not to renew the contracts with the three MFIs for registering subscribers and collecting payments. Interviews with senior INSS officials suggested that this decision was motivated by a number of factors, including INSS's perspective that this was a low-priority project and a political backlash against MFIs, which were being accused of predatory lending by the government. We discuss more details about these institutional changes and their implications for our research in Section 6.

\section{RESEARCH DESIGN}

\subsection{Data collection and study design}

To measure the determinants of insurance enrollment as well as the causal effects of having insurance, we implemented an evaluation that randomly varied the costs (financial, informational, and convenience) of signing up for health insurance for each individual. Data collection involved a baseline and one-year follow-up survey of a sample of eligible participants in addition to consolidated administrative data on insurance affiliation from INSS.

Appendix A presents a summary of the project timeline. Between March and June 2007, a few months after the insurance program was rolled out to informal sector workers, a baseline survey was administered to a representative sample of vendors in the three largest open-air markets in central Managua. These markets were chosen because they were likely to contain a large population of uninsured informal sector workers who were microfinance clients. Although clearly this method did not produce a population-representative sample of individuals eligible for the insurance product, sampling the largest markets was a cost-effective means of locating a relatively representative subpopulation of informal sector vendors. Moreover, since these workers are slightly better off than either vendors in very small markets or informal sector workers outside of the retail market, they were presumed to be a key target group of the new insurance scheme. However, it is important to bear in mind that our conclusions pertain to this specific subpopulation.

The baseline survey collected information in two rounds on demographic characteristics, prior and current health services utilization, socioeconomic characteristics, and health-care expenditures. Government ID numbers were collected to match respondents to health insurance enrollment data subsequently provided by the government. The first round of the baseline survey was conducted in March and April 2007 in a section of the Mercado Oriental, Managua's largest marketplace. The second round was conducted in June and July 2007 in the remaining portion of the Mercado Oriental and in the slightly smaller Mercados Huembes and Iven Montenegro marketplaces. ${ }^{6}$

\footnotetext{
${ }^{5}$ The USAID-funded Private Sector Partnerships-One project (PSP-One) supported the INSS in coordination and training activities between July 2006 and March 2007. Initial trainings took place prior to the project's expected roll out in July/August 2006 and were replicated in October and November 2006 by the INSS. The project was actually rolled out in January 2007 , due mainly to delays caused by the presidential elections in November 2006 and the initiation of the new administration in February 2007.

${ }^{6}$ In addition, the baseline survey also included respondents in four other smaller markets; because these respondents were not followed over time, we do not include them in our analysis.
} 
Before the first round of the baseline survey, we conducted a census of market booths to define the sampling frame of possible respondents. Participants deemed eligible through the census were selected randomly and administered the full survey. ${ }^{7}$ Eligibility depended on age (between ages 18 and 54), having a government ID, being the owner of the booth, and lacking health insurance coverage. ${ }^{8}$ The first two criteria were determined by government eligibility requirements, while the second two were research design considerations intended to target those with relatively high demand for insurance. Appendix B, Panel A, presents the completion rates of the baseline survey. While overall completion rates were relatively low at 51 and $53 \%$ for the two rounds, the main reasons for nonparticipation were inability to locate vendors at their booths $(22 \%)$ and ineligibility of vendors on either the age criterion or their lack of an on-hand government ID (15.1\%). Rates of refusal among eligible vendors who were found at their booths were low $(7.7 \%)$. Nonetheless, sample selection based on the availability of respondents and possession of IDs may affect the external validity of the study. In particular, those who were available and carried government IDs might be relatively stable or cooperative types - and as such, perhaps more likely than the average informal worker to sign up for government-sponsored insurance. In this case, our results would overstate the impact of introducing a health insurance program to all workers. Alternatively, absent workers may have higher demand for insurance if, for instance, they are sicker or have larger families. On the other hand, it may simply be the case that all workers periodically take days off from the market, making those missing on survey days a quasirandom sample. Hence, while sample selection bias may limit the generalizability of the study, it is also difficult to draw conclusions about the likely nature of the bias. In terms of internal validity, participation rates do not generate a bias since we randomly allocated subsidies for health insurance only after individuals had agreed to participate, so selection is orthogonal to treatment assignment.

During the spring of 2008, 2807 respondents were approached for the follow-up survey, and 2610 $(93 \%)$ were successfully reinterviewed. ${ }^{9}$ The reasons for attrition are presented in Appendix B, Panel B. Information on enrollment - including whether at INSS or an MFI - was provided by administrative data from INSS, and linked to our survey data via government ID numbers.

\subsection{Sample characteristics}

Our analysis is restricted to the respondents who completed interviews at both baseline and follow-up and had valid voucher data (2608). Table I presents key characteristics of the sample. In addition to presenting averages across the pooled sample, we show mean values separately for respondents who were and were not MFI loan recipients at the time of the first survey.

The average respondent was 38 years old and had 9.3 years of education. About $35 \%$ of respondents were male and $70 \%$ were married or had a common-law spouse, a proportion higher than the national average of $56 \%$ (ENDESA household survey, Nicaragua, 2006). Respondents had two children on average, with two-thirds having at least one child under age 12, the maximum age for coverage of dependents by the INSS health insurance. Only 3\% of the sample was pregnant or had a spouse who was pregnant.

MFI clients were about 2 years older on average than non-MFI clients, and were more likely to be female ( 72 vs $61 \%$, respectively). In addition, MFI clients had slightly more children.

\footnotetext{
${ }^{7}$ In round one, the census of the Mercado Oriental recorded all of individuals who worked in a booth in the past 12 months. The market was divided into 98 blocks using a map of the market; 25 blocks were excluded from the sample either because they were dangerous or had no businesses. We then randomly selected eligible respondents stratified by gender, marital status, and MFI client status. To oversample MFI clients, all booths identified in the census as containing an eligible MFI client were selected. ${ }^{8}$ Participants were required to display their government ID cards or a legible copy of their card. Surveyors offered vendors the opportunity to bring their cards on a subsequent day if they were interested in participating and revisited vendors three times before disqualifying them as ineligible.

${ }^{9}$ Baseline characteristics do not vary systematically between the full sample of baseline respondents and the 2610 who were interviewed one year later and used for the analysis in this paper (results not shown).
} 
Table I. Baseline sample characteristics

\begin{tabular}{|c|c|c|c|c|c|c|c|}
\hline \multirow[b]{2}{*}{ Panel A: Demographic characteristics } & \multicolumn{2}{|c|}{ All $(N=2608)$} & \multicolumn{2}{|c|}{ MFI client $(N=1013)$} & \multicolumn{2}{|c|}{ Non-MFI client $(N=1595)$} & \multirow[b]{2}{*}{ Difference } \\
\hline & Mean & SD & Mean & SD & Mean & SD & \\
\hline$\overline{\text { Age }}$ & 37.79 & 9.28 & 39.05 & 8.57 & 36.98 & 9.63 & $2.07^{* * *}$ \\
\hline Male & 0.35 & 0.48 & 0.28 & 0.45 & 0.39 & 0.49 & $-0.11^{* * *}$ \\
\hline Years education & 9.26 & 4.22 & 9.25 & 4.15 & 9.27 & 4.27 & -0.02 \\
\hline Married & 0.70 & 0.46 & 0.70 & 0.46 & 0.70 & 0.46 & 0.00 \\
\hline Number of children & 2.04 & $\begin{array}{l}0.40 \\
1.52\end{array}$ & 2.22 & $\begin{array}{l}0.40 \\
1.52\end{array}$ & 1.93 & $\begin{array}{l}0.40 \\
1.52\end{array}$ & $0.29^{* * *}$ \\
\hline With under 12 children & 0.66 & 0.47 & 0.66 & 0.48 & 0.67 & 0.47 & -0.01 \\
\hline \multirow[t]{2}{*}{ Pregnant } & 0.03 & 0.18 & 0.03 & 0.18 & 0.03 & 0.17 & 0.00 \\
\hline & \multicolumn{2}{|c|}{ All } & \multicolumn{2}{|c|}{ MFI client } & \multicolumn{2}{|c|}{ Non-MFI client } & \\
\hline Panel B: Economic characteristics & Mean & SD & Mean & $\mathrm{SD}$ & Mean & SD & Difference \\
\hline Monthly income & 273.89 & 380.34 & 297.22 & 404.12 & 258.77 & 363.45 & $38.44^{* * *}$ \\
\hline Proportion with savings & 0.29 & 0.46 & 0.28 & 0.45 & 0.30 & 0.46 & $\begin{array}{r}50.44 \\
-0.02\end{array}$ \\
\hline Monthly savings & 25.11 & 158.51 & 23.40 & 157.89 & 26.19 & 158.95 & -2.78 \\
\hline Last year's savings Balance & 145.73 & 574.94 & 141.45 & 609.66 & 148.45 & 551.85 & -7.00 \\
\hline owns home & 0.76 & 0.42 & 0.80 & 0.40 & 0.74 & 0.44 & $0.06^{* * *}$ \\
\hline Total household health-care costs & 84.46 & 171.62 & 88.67 & 174.38 & 81.78 & 169.85 & 6.89 \\
\hline Total health-care costs for respondent & 46.50 & 114.44 & 51.68 & 128.77 & 43.20 & 104.20 & $8.48^{*}$ \\
\hline Last visit cost for respondent & 17.77 & 59.98 & 20.79 & 82.05 & 15.86 & 39.95 & $4.93^{* *}$ \\
\hline Proportion MFI Clients & 0.39 & 0.49 & & & & & \\
\hline
\end{tabular}

Notes: This table presents sample statistics from 2608 respondents baseline survey data. The last column presents differences in means of each variable between MFI Clients and non-MFI clients. * Significant at $10 \% ;{ }^{* *}$ significant at $5 \%$; $* *$ significant at $1 \%$.

Respondents had an average monthly income of US\$274 (Panel B). ${ }^{10}$ Average monthly disposable income after business and household expenses was reported at US\$25. However, only $29 \%$ declared having disposable income at month end. Almost 58\% had an outstanding loan, and about one-third had a loan with an MFI (not reported). MFI clients reported higher monthly income (by approximately US\$38), but their likelihood of savings and average savings balance were about the same as non-MFI clients. MFI clients spent about US\$8 more on health care for themselves than did their counterparts.

In terms of health status, $80 \%$ of those surveyed reported being sick in the year before the baseline survey, with a mean value of 2.6 episodes (Table II, Panel A). Many respondents reported chronic or common recurring conditions such as kidney problems, diabetes, hypertension, respiratory problems, vision or hearing problems, stress, headaches, or allergies. Table II (Panel B) summarizes information on the last illness respondents reported experiencing in the previous 12 months. Almost half were related to allergies or respiratory illnesses such as cold or flu and $60 \%$ reported suffering from flu symptoms in the previous year. The majority of reported illnesses were minor conditions. Only $11 \%$ missed more than a week of work due to their last illness and the majority $(57 \%)$ missed zero days of work (not reported). Our data do not point to any significant advantage of targeting MFI clients (or non-MFI clients) for microinsurance programs based on relative health status. Although MFI clients were slightly more likely than non-MFI clients to report having diabetes, stress, and hypertension in the year before the baseline, they were less likely to report smoking.

In terms of baseline health service utilization, pharmacies were the most visited of any health facility, with $73 \%$ of all respondents reporting at least one visit. Of those who visited, the average was three pharmacy visits in the prior year (Table III). Private sector facilities were utilized more than public sector facilities, with $29 \%$ reporting visits to private doctors and $15 \%$ to private clinics/hospitals in the prior

\footnotetext{
${ }^{10}$ Reported income for respondents and their spouse was reported in Nicaraguan Cordoba was converted to US Dollars at the rate of US\$1 $=18.7 \mathrm{NIO}$.
} 
Table II. Baseline health characteristics

\begin{tabular}{|c|c|c|c|c|}
\hline \multirow[b]{2}{*}{ Panel A: Health characteristics } & All $(N=2608)$ & MFI client $(N=1013)$ & Non-MFI client $(N=1595)$ & \multirow[b]{2}{*}{ Difference } \\
\hline & \multicolumn{3}{|c|}{ Mean } & \\
\hline Ever sick in 2007 & 0.80 & 0.80 & 0.80 & 0.00 \\
\hline Times sick in 2007 & 2.57 & 2.60 & 2.55 & 0.05 \\
\hline Days waited to see doctor & 4.50 & 4.74 & 4.34 & 0.40 \\
\hline Smokes & 0.15 & 0.14 & 0.16 & $-0.03^{*}$ \\
\hline Diabetes & 0.06 & 0.07 & 0.05 & $0.02 * *$ \\
\hline Hypertension & 0.19 & 0.21 & 0.17 & $0.03^{* *}$ \\
\hline Heart problems & 0.05 & 0.06 & 0.05 & 0.01 \\
\hline Respiratory problems & 0.14 & 0.13 & 0.14 & -0.01 \\
\hline Physical limitations & 0.01 & 0.01 & 0.01 & 0.00 \\
\hline Sight/hearing limitations & 0.25 & 0.27 & 0.24 & 0.03 \\
\hline $\begin{array}{l}\text { Stress } \\
\text { Sto }\end{array}$ & 0.15 & 0.17 & 0.14 & $0.03^{* *}$ \\
\hline Kidney problems & 0.25 & 0.27 & 0.24 & 0.02 \\
\hline Cancer & 0.01 & 0.01 & 0.01 & 0.00 \\
\hline Headaches & 0.40 & 0.40 & 0.40 & 0.01 \\
\hline Skin problems & 0.08 & 0.08 & 0.08 & 0.00 \\
\hline Allergies & 0.15 & 0.14 & 0.15 & -0.01 \\
\hline Flu & 0.60 & 0.60 & 0.60 & 0.00 \\
\hline Fever & 0.32 & 0.30 & 0.33 & -0.03 \\
\hline Vomiting & 0.08 & 0.08 & 0.09 & -0.02 \\
\hline Diarrhea & 0.10 & 0.10 & 0.09 & 0.00 \\
\hline Cough & 0.19 & 0.18 & 0.19 & -0.02 \\
\hline Chest pains & 0.15 & 0.14 & 0.15 & -0.01 \\
\hline Back pains & 0.26 & 0.27 & 0.26 & 0.02 \\
\hline Dizziness & 0.17 & 0.15 & 0.18 & $-0.03^{* *}$ \\
\hline \multicolumn{5}{|l|}{ Panel B: Last illness } \\
\hline Allergies or respiratory illness & 0.49 & 0.46 & 0.50 & -0.04 \\
\hline Renal infection or diabetes & 0.14 & 0.16 & 0.13 & 0.03 \\
\hline Circulatory problems & 0.07 & 0.08 & 0.07 & 0.01 \\
\hline Diarrhea or Digestive problems & 0.05 & 0.05 & 0.05 & 0.00 \\
\hline Arthritis & 0.04 & 0.05 & 0.04 & 0.01 \\
\hline Gynocology visit & 0.03 & 0.03 & 0.03 & 0.00 \\
\hline Dengue or malaria & 0.02 & 0.01 & 0.02 & -0.01 \\
\hline Skin infection & 0.01 & 0.01 & 0.02 & 0.00 \\
\hline Other & 0.16 & 0.15 & 0.16 & -0.01 \\
\hline
\end{tabular}

Notes: This table presents sample statistics from 2608 respondents baseline survey data. The last column presents differences in means of each variable between MFI Clients and non-MFI clients. ${ }^{*}$ Significant at $10 \%$; ${ }^{* *}$ significant at $5 \%$; ${ }^{* *}$ significant at $1 \%$.

year, compared to $16 \%$ reporting visits to public health centers and $9 \%$ to public hospitals. Only $1 \%$ of survey respondents reported visiting an INSS clinic (EMP) in the year prior to the baseline survey. ${ }^{11}$ The high representation of pharmacy visits is especially notable because public health centers and hospitals are supposed to provide medication free of charge, but anecdotally lack inventory on a regular basis. Results from focus group discussions confirmed this anecdotal evidence. Busy market workers often do not bother to visit a free clinic, where they risk finding out their medication is unavailable after waiting hours to see a doctor. Instead, they generally prefer to go to a pharmacy, where a pharmacist might also recommend a medication and provide it immediately and pay for the service.

Correspondingly, respondents reported significantly lower mean expenditures at subsidized public health centers (US\$0.26; $N=407$ ) than at pharmacies (US\$42.67; $N=1878$ ) or for laboratory tests (US\$25.67; $N=689)$. Those attending a private doctor $(N=738)$ reported spending US $\$ 16.97$ in annual

\footnotetext{
${ }^{11}$ EMPs primarily provide services to those eligible for INSS health insurance, although many offer services to noninsured paying customers as well.
} 
Table III. Health facilities visited in the past year at baseline

\begin{tabular}{|c|c|c|c|c|c|c|c|}
\hline \multirow[b]{2}{*}{ Panel A: all $(N=2608)$} & \multicolumn{2}{|c|}{ Visited } & \multicolumn{2}{|c|}{ Number of visits } & \multicolumn{3}{|c|}{ Expenditure } \\
\hline & Mean & SD & Mean & SD & Mean & SD & Median \\
\hline Pharmacy & 0.73 & 0.45 & 3.20 & 4.15 & 42.67 & 91.21 & 16.04 \\
\hline Private doctor & 0.29 & 0.45 & 2.18 & 2.64 & 16.97 & 44.17 & 6.42 \\
\hline Laboratory & 0.27 & 0.44 & 2.08 & 2.77 & 25.67 & 66.93 & 10.70 \\
\hline Social security Health clinic (EMP) & 0.01 & 0.08 & 3.88 & 5.45 & 14.88 & 47.25 & 0.00 \\
\hline Private clinic/hospital & 0.15 & 0.35 & 2.31 & 2.17 & 24.04 & 73.63 & 6.42 \\
\hline Public (MINSA) health center & 0.16 & 0.36 & 2.80 & 3.10 & 0.26 & 2.00 & 0.00 \\
\hline \multirow[t]{2}{*}{ Public (MINSA) hospital } & 0.09 & 0.28 & 2.79 & 5.20 & 2.33 & 16.22 & 0.00 \\
\hline & \multicolumn{2}{|c|}{ Visited } & \multicolumn{2}{|c|}{ Number of visits } & \multicolumn{3}{|c|}{ Expenditure } \\
\hline Panel B: $M F I$ clients $(N=1013)$ & Mean & SD & Mean & $\mathrm{SD}$ & Mean & SD & Median \\
\hline Pharmacy & 0.73 & 0.44 & 3.47 & 4.78 & 45.19 & 89.49 & 16.04 \\
\hline Private doctor & 0.32 & 0.47 & 2.38 & 3.52 & 18.37 & 57.05 & 5.35 \\
\hline Laboratory & 0.26 & 0.44 & 2.06 & 1.89 & 32.04 & 85.81 & 10.70 \\
\hline Social security health clinic (EMP) & 0.01 & 0.10 & 3.80 & 6.11 & 24.33 & 60.98 & 0.00 \\
\hline Private clinic/hospital & 0.15 & 0.36 & 2.57 & 2.52 & 26.11 & 84.59 & 5.35 \\
\hline Public (MINSA) health center & 0.14 & 0.35 & 2.58 & 2.81 & 0.34 & 2.38 & 0.00 \\
\hline \multirow[t]{2}{*}{ Public (MINSA) hospital } & 0.09 & 0.28 & 2.45 & 2.45 & 3.32 & 19.24 & 0.00 \\
\hline & \multicolumn{2}{|c|}{ Visited } & \multicolumn{2}{|c|}{ Number of visits } & \multicolumn{3}{|c|}{ Expenditure } \\
\hline Panel C: non-MFI clients $(N=1595)$ & Mean & SD & Mean & $\mathrm{SD}$ & Mean & SD & Median \\
\hline Pharmacy & 0.72 & 0.45 & 3.03 & 3.69 & 41.05 & 92.31 & 16.04 \\
\hline Private doctor & 0.26 & 0.44 & 2.03 & 1.68 & 15.90 & 30.83 & 6.42 \\
\hline Laboratory & 0.27 & 0.45 & 2.10 & 3.19 & 21.83 & 41.02 & 10.70 \\
\hline Social security health clinic (EMP) & 0.00 & 0.07 & 4.00 & 4.83 & 1.38 & 3.64 & 0.00 \\
\hline Private clinic/hospital & 0.14 & 0.35 & 2.13 & 1.88 & 22.61 & 65.14 & 6.55 \\
\hline Public (MINSA) health center & 0.17 & 0.37 & 2.92 & 3.24 & 0.21 & 1.76 & 0.00 \\
\hline Public (MINSA) hospital & 0.09 & 0.28 & 3.00 & 6.35 & 1.70 & 14.01 & 0.00 \\
\hline
\end{tabular}

Notes: This table presents sample statistics from 2608 respondents baseline survey data. Proportion of the respondents who visited each provider in the past year. Number of respondent total visits and amount the respondent spent includes only those who actually went to that facility. Amount spent is presented in dollars.

visits, which may reflect the prevalence of both NGOs that provide health services at subsidized costs for low-income groups in Nicaragua and private doctors and nurses who practice out of their homes at reduced fees. Similarly, among those who visited a hospital, respondents spent US\$24.04 at private hospitals $(N=378)$ and US\$2.33 at public hospitals $(N=227)$. The median amount spent at each facility was substantially lower than the average.

On average, total expenses for health care over the year before the baseline survey were quite substantial, at US\$84.46 (or $31 \%$ of mean household income) for the respondent and children under age 12 and US\$46.50 for the respondent alone (Table I, Panel B). However, it is important to note that average total expenses over the year were substantially less than annual insurance premiums under the new program, which were US $\$ 186 .{ }^{12}$ In fact, only $11 \%$ of respondents spent more than $\$ 186$ per year on themselves and their children under age 12 during the year before the program. The fact that premiums well exceed expected OOP expenses for the vast majority of individuals indicates potentially low

\footnotetext{
${ }^{12}$ These expenditures are substantially higher than out-of-pocket family health costs in the general population (US\$28) according to the 2003 National ENDESA survey in Nicaragua, even considering an additional $\$ 12$ adjustment for inflation over the period, though much of the difference surely reflects an urban bias.
} 
willingness to pay for the new health insurance plan, which is likely to be the fundamental reason for the low rates of enrollment and retention found. On the other hand, if individuals had perceived that the insurance would provide access to shorter waiting times, higher quality, or more convenient services, we might have seen a higher demand for the insurance product.

Baseline differences between MFI clients' and non-MFI clients' health expenditures were small overall. MFI clients were less likely to use public facilities, and as a result reported slightly higher health-care expenditures (approximately US\$8 more; Table I Panel B), mainly driven by laboratory costs.

\subsection{Randomization process}

To evaluate factors influencing health insurance enrollment and also generate random variation in insurance coverage, our research design randomly assigned individuals to treatment arms with differing prices and enrollment procedures. Randomization was conducted at the individual level. At the end of the baseline survey, participants were invited to choose a lottery ticket out of a stack of unmarked, presealed envelopes. The possible lottery prizes included a blank ticket (no prize); an INSS brochure detailing the insurance product; a brochure accompanied by a 6-month insurance subsidy with instructions to sign up at the INSS office; or a brochure accompanied by a 6-month insurance subsidy with instructions to sign up at an MFI office. ${ }^{13}$ The 6-month subsidy was worth approximately US\$96 and was provided in the form of a voucher; respondents were told that payments would be made on their behalf directly to the INSS. The distribution of lottery tickets is presented in Appendix C, which also presents the attrition rates by randomization group.

In addition, immediately following the second round of the baseline survey, a random sample of 112 respondents who had been offered a 6-month subsidy and 63 respondents who had been offered no subsidy - none of whom had yet subscribed - were offered the opportunity to sign up for health insurance at their market booth. Surveyors were trained to fill out the registration forms on site and were accompanied by a photographer who took required photos.

\section{EMPIRICAL STRATEGY}

Most cross sectional or panel studies that examine the impact of being insured suffer from potential omitted variable bias, in which an individual's unobservable propensity to purchase insurance is related to his/her underlying health profile or risk preferences. This makes causal inference of the impact of health insurance on health and related outcomes difficult because if those who have a greater risk of illness are both more likely to enroll in health insurance and more likely to be sick, the observed impact of having insurance is biased. A randomized study design such as that used in this evaluation reduces potential bias due to selection effects by guaranteeing that, in expectation, comparison groups are composed of the same underlying types. Indeed, Appendix D verifies that random assignment in this case achieved comparison groups that were similar on observable baseline characteristics. There are some differences between insurance subsidy and control groups; however, these differences are small in magnitude. The results are similar across MFI clients and non-MFI clients (results not shown), which is unsurprising given that the sample was stratified by MFI membership prior to randomization.

\footnotetext{
${ }^{13}$ There were also two additional treatment arms that gave a brochure accompanied by a two-month insurance subsidy with instructions to sign up at the INSS office and one that gave a brochure accompanied by a two-month insurance subsidy with instructions to sign up at an MFI. These individuals were not interviewed at the follow-up survey and we do not include them in the analysis of this article. In the second round, only three prizes were offered: an INSS brochure, a 6-month insurance subsidy (instructed to sign up at INSS office), and a 6-month subsidy (instructed to sign up at MFI).
} 
To measure the determinants of insurance enrollment, including the amount of subsidy received and the assigned location for enrollment, we estimate the following regression equation:

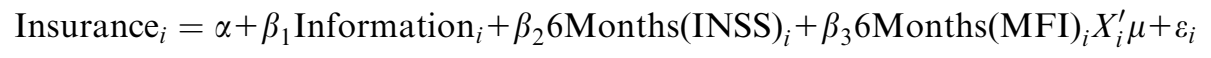

where 'Insurance' is an indicator if respondent ' $i$ ' signed up for health insurance. 'Information,' '6 Months(INSS),' and '6 Months(MFI)' are indicators of the randomized lottery received. The pure control group is the omitted category. The vector of control variables, $X$, includes age, age squared, gender, years of education, marital status, and market fixed effects. In some specifications, we also control for baseline health expenditures and health status indicators. Data are pooled from both rounds of baseline surveys and round fixed effects are included. To test whether MFI clients respond differentially to affiliation assignment, we also estimate Equation 1 separately by MFI client status.

In the second stage, we evaluate the effects of health insurance on health-care utilization and expenditures. The randomized first stage predicting health insurance enrollment - specification (1) above - allows for an instrumental variables (IV) analysis of the effects of insurance. In the second stage, we estimate

$$
Y_{i}=\alpha+\beta_{1} \text { Insurance }_{i}+X_{i}^{\prime} \mu+\varepsilon_{i}
$$

where ' $Y$ ' is the outcome variable of interest (health expenditures or number of health-care visits at follow-up) and 'Insurance' enrollment is instrumented with the vector of treatment indicators (blank ticket/no-incentive control; INSS brochure/information only; subsidy for enrollment at INSS office; subsidy for enrollment at MFI office). The F-statistic of the excluded instruments is large, at 213.33, indicating a strong first-stage effect of the subsidies. It is important to keep in mind that an IV model estimates a local average treatment effect, or the mean effect of insuring those on the margin of enrolling if offered a subsidy, rather than the population average effect. Hence, these estimates do not tell us the expected impact of providing insurance coverage to all informal sector workers.

To estimate the determinants of retention, we re-estimate (1) with the dependent variable indicating whether the respondent was still paying for health insurance at the follow-up survey and only include the 530 individuals who had enrolled in the health insurance program. We examine both the impact of receiving an insurance subsidy as well as potential differential effects of being an MFI client. Because of the small number of enrollees in the control and information-only treatment groups, we use only the 6-month subsidy groups to study differential effects of signing up at an MFI on retention. It is worth noting that while signing up at an MFI was randomized, estimating the effects of place of affiliation on retention is complicated by the fact that this specification is estimated only among those who chose to sign up for insurance - which is endogenously determined.

\section{RESULTS}

\subsection{Take-up of insurance}

Overall, $20.3 \%$ of our sample enrolled in the insurance scheme. Table IV presents the OLS regression results predicting take-up. Those receiving the informational brochure alone were approximately five percentage points less likely to enroll in the insurance program relative to the control group who received nothing (Column 1). This potentially indicates that expectations about the product were overly optimistic, which is consistent with the fact that all those in the control group who enrolled dropped out of the program by the second year. Those receiving a 6-month subsidy and assigned to register at the INSS office were 33 percentage points more likely to purchase insurance than the control group, and those receiving a 6-month subsidy and assigned to register at a participating MFI were 28 percentage points more likely to enroll relative to the controls. 
Table IV. Determinants of insurance enrollment

\begin{tabular}{|c|c|c|c|c|}
\hline \multirow[b]{2}{*}{ Dependent variable: signed up for Insurance $(0 / 1)$} & \multicolumn{2}{|c|}{ All } & \multirow{2}{*}{$\frac{\text { MFI client }}{\text { (3) }}$} & \multirow{2}{*}{$\begin{array}{c}\text { Non-MFI client } \\
\text { (4) }\end{array}$} \\
\hline & (1) & (2) & & \\
\hline \multirow[t]{2}{*}{ Information only } & $-0.049^{* *}$ & $-0.058^{* *}$ & -0.051 & $-0.093^{* *}$ \\
\hline & {$[0.023]$} & {$[0.028]$} & {$[0.041]$} & {$[0.041]$} \\
\hline \multirow[t]{2}{*}{ Six-month subsidy - INSS } & $0.333^{* * *}$ & $0.336^{* * *}$ & $0.384^{* * *}$ & $0.275^{* * *}$ \\
\hline & {$[0.028]$} & {$[0.033]$} & {$[0.051]$} & {$[0.046]$} \\
\hline \multirow[t]{2}{*}{ Six-month subsidy - MFI } & $0.281^{* * *}$ & $0.277^{* * *}$ & $0.313^{* * *}$ & $0.223^{* * *}$ \\
\hline & {$[0.028]$} & {$[0.033]$} & {$[0.048]$} & {$[0.047]$} \\
\hline \multirow[t]{2}{*}{ Male } & -0.023 & -0.024 & -0.007 & -0.032 \\
\hline & {$[0.015]$} & {$[0.017]$} & {$[0.030]$} & {$[0.021]$} \\
\hline \multirow[t]{2}{*}{ Education } & 0.002 & 0.002 & 0.001 & 0.003 \\
\hline & {$[0.002]$} & {$[0.002]$} & {$[0.003]$} & {$[0.003]$} \\
\hline \multirow[t]{2}{*}{ Married } & 0.014 & 0.023 & -0.002 & 0.037 \\
\hline & {$[0.016]$} & {$[0.018]$} & [0.029] & {$[0.023]$} \\
\hline \multirow[t]{2}{*}{ MFI client } & $0.033^{* *}$ & $0.031^{*}$ & & \\
\hline & {$[0.015]$} & {$[0.016]$} & & \\
\hline \multirow[t]{2}{*}{ Number of children } & $-0.015^{* * *}$ & $-0.012^{* *}$ & $-0.032^{* * *}$ & 0.001 \\
\hline & {$[0.005]$} & {$[0.006]$} & {$[0.010]$} & {$[0.008]$} \\
\hline \multirow[t]{2}{*}{ Has children under 12} & $0.030^{*}$ & $0.035^{*}$ & $0.111^{* * *}$ & -0.015 \\
\hline & {$[0.017]$} & {$[0.019]$} & {$[0.030]$} & {$[0.024]$} \\
\hline \multirow[t]{2}{*}{ Log income } & & 0.013 & 0.015 & 0.013 \\
\hline & & {$[0.008]$} & {$[0.015]$} & {$[0.009]$} \\
\hline \multirow[t]{2}{*}{ Has any savings } & & 0.009 & 0.002 & 0.007 \\
\hline & & {$[0.017]$} & {$[0.028]$} & {$[0.022]$} \\
\hline \multirow[t]{2}{*}{ Smokes } & & 0.013 & -0.028 & 0.038 \\
\hline & & {$[0.021]$} & {$[0.032]$} & {$[0.028]$} \\
\hline \multirow[t]{2}{*}{ Any chronic disease } & & $0.044^{* *}$ & 0.034 & $0.053^{* *}$ \\
\hline & & {$[0.018]$} & {$[0.027]$} & {$[0.023]$} \\
\hline \multirow[t]{2}{*}{ Ever sick } & & 0.003 & 0.003 & -0.026 \\
\hline & & [0.059] & {$[0.119]$} & {$[0.069]$} \\
\hline \multirow[t]{2}{*}{ Log costs of health care } & & -0.001 & $-0.012^{*}$ & 0.006 \\
\hline & & {$[0.005]$} & {$[0.007]$} & {$[0.006]$} \\
\hline \multirow[t]{2}{*}{ Number of visits to provider } & & 0.000 & 0.002 & -0.001 \\
\hline & & {$[0.001]$} & {$[0.002]$} & {$[0.002]$} \\
\hline \multirow[t]{2}{*}{ Any visit to provider } & & 0.023 & 0.131 & -0.015 \\
\hline & & {$[0.065]$} & {$[0.127]$} & {$[0.077]$} \\
\hline \multirow[t]{2}{*}{ Constant } & 0.028 & -0.098 & $-0.472^{*}$ & 0.071 \\
\hline & {$[0.116]$} & {$[0.136]$} & {$[0.245]$} & {$[0.165]$} \\
\hline Observations & 2608 & 2215 & 867 & 1348 \\
\hline$R^{2}$ & 0.22 & 0.23 & 0.30 & 0.21 \\
\hline
\end{tabular}

Notes: Standard errors in brackets. This table presents OLS regressions on signing up for health insurance. Each column also includes market fixed effect (location of work for the respondent) and round fixed effects as well as controls for age and age squared. Any chronic disease includes diabetes, hypertension, cardiac problems, physical disability, psychological problems, kidney problems, and cancer. ${ }^{*}$ Significant at $10 \% ;{ }^{* *}$ significant at $5 \% ;{ }^{* * *}$ significant at $1 \%$.

The difference in take-up between those assigned to enroll at an MFI versus at INSS is statistically significant and negative (coefficient $-0.054 ; p$-value $=0.034$; not shown). The results of focus group interviews held in 2008 shed light on this finding, indicating that many survey respondents did not understand the purpose of the MFI serving as an agent for the insurance and preferred enrolling directly at the INSS. ${ }^{14}$ Other reports indicated coordination problems between central MFI management and MFI branches about the enrollment process. Overall, $98.5 \%$ of individuals who enrolled adhered to

\footnotetext{
${ }^{14}$ In some cases, the INSS reported that some respondents assigned to sign up at MFIs attempted to first sign up at INSS but were turned away and told that their lottery award was only valid at an MFI, suggesting that, were clients able to enroll at either location, the difference between MFI and non-MFI assignment may disappear.
} 
their randomly assigned location for enrollment. ${ }^{15}$ Of those who enrolled at an MFI, $47 \%$ went to ProCredit, $15 \%$ went to Findesa, and $37 \%$ went to ACODEP (results not shown). ${ }^{16}$

There was no statistically significant difference in take-up between men and women; there was no significant difference in take-up between married and unmarried respondents. Controlling for the total number of children in the family, having children under the age of 12 (the age of eligible dependents) increased the likelihood of take-up by approximately 3 percentage points; however, the total number of children was negatively related to uptake. Conditional on the above variables, age (not shown) and education had no additional explanatory power.

Baseline health expenditures and utilization of health care had very little predictive power in determining enrollment. Similarly, income had no statistically significant effect on insurance take-up, controlling for all other factors, which may reflect the high degree of correlation between income and other household characteristics. However, having a chronic or commonly recurring disease, such as diabetes or hypertension, was positively associated with rates of uptake, increasing the likelihood of enrollment by 4.4 percentage points and indicating some degree of adverse selection in this type of voluntary insurance program.

Certain markets were associated with significantly higher take-up than others. Vendors in the Huembes market had higher take-up rates than those in the Oriental market, an effect that remains significant after controlling for the respondents' own income, indicating unobservable differences across marketplaces in latent demand for health insurance. For instance, vendors in Huembes market tend to have longer market tenure than vendors in other markets in Managua because of the reportedly better conditions, greater safety, and more 'upscale' clientele. Additionally, Huembes market is anecdotally associated with a greater level of formalization (more officially registered businesses) than some of the other markets.

In total, the basic patterns in enrollment are relatively similar between MFI clients and non-MFI clients. Subsidies are the most important determinants of take-up. Having children under 12 was a more important determinant among MFI clients than among non-MFI clients. Baseline costs of health care also seem to have opposite relationships with take-up between MFI clients and non-MFI clients. However, these differences are small in magnitude.

\subsection{On-site enrollment}

Individuals enrolling, for insurance, at either the INSS central office or at an MFI were required to provide photocopies of their government identification cards, two passport size photos, and birth certificates of all beneficiaries. They also had to complete a registration form and then travel to the INSS or MFI office and wait in line to register in person. According to our survey, this process took about one day's time, a substantial cost for small business owners who would need to find someone to watch their market booth or forego a day's revenue.

Given the potential barriers to enrollment posed by these costs, a random sample of 175 nonenrolled respondents (112 who had been offered a 6-month subsidy and 63 who had been offered no subsidy)

\footnotetext{
${ }^{15}$ Of those who were clients of a participating MFI, the majority of those receiving the 6 month subsidy and who were told to sign up with an MFI signed up at their own institution (77 percent of ACODEP clients, 57 percent of Findesa clients, and 85 percent of ProCredit clients). Of those who were a client of a different MFI or who were not a MFI client, affiliation was fairly evenly split at ACODEP and Procredit, with low affiliation rates at Findesa.

${ }^{16}$ The higher uptake for ProCredit clients is likely influenced by the large and convenient branch located near the Oriental Market where many respondents worked. In addition, key informant interviews and our monitoring of the MFIs' activities related to the program revealed higher levels of effort in participating in the project, including training its staff and arranging events to market the program to its clients. Administrative problems may also have influenced the results. While ACODEP had a marketing effort in place, we learned that its branch manager in the Oriental Market was changed shortly after our baseline survey and that the new manager was not informed of either the demonstration project nor of the MFI's commitment to sign up survey respondents. As a result, many people were turned away when they tried to sign up.
} 
were given the opportunity to enroll for health insurance at their market booth. On-site enrollment eliminated respondents' travel costs and reduced the time costs related to taking photographs and making copies of their ID cards. In addition, it minimized potential psychological influences on enrollment such as procrastination or imperfect recall and addressed constraints imposed by uncertainty regarding the enrollment process.

Providing respondents the convenience of signing up for insurance directly from their market stall had a large effect on enrollment rates. Within the market that was chosen for the on-site enrollment, only $1 \%$ of those receiving information alone enrolled compared to $23 \%$ of those who also received the opportunity to enroll on the spot but no financial subsidy. Similarly, 34\% of those offered the 6-month subsidy without on-site enrollment purchased insurance, compared to $70 \%$ of those offered both onthe-spot enrollment and the 6-month subsidy (results not shown). In sum, simply reducing the time costs of going to an office to sign up (without offering a subsidy) had more than half the effect of a 6-month subsidy worth approximately $\$ 100 .{ }^{17}$ See Thornton et al. (2007) for more details.

\subsection{Effect of insurance: utilization and expenditures}

We next use follow-up survey data to examine the effects of insurance coverage on health-care utilization and expenditures after one year. ${ }^{18}$ In light of the large differences in enrollment between those offered 6-month subsidies versus information only, we instrument for insurance coverage using treatment assignment with specification (1), that is, having been offered a 6-month subsidy. ${ }^{19}$ The IV estimates are presented in Table V.

Overall, enrolling in health insurance did not lead to an increase in the probability of seeking any health care from a provider, but it did significantly impact substitution away from the use of public and private facilities into EMP facilities covered by the insurance. Those who were insured were 42.7 percentage points more likely to have visited an EMP in the prior year, 8.9 percentage points less likely to have visited a private clinic, 6.3 percentage points less likely to have visited a public health center, and 11.5 percentage points less likely to have visited a public hospital than the uninsured. No differences between MFI and non-MFI clients were found in the general pattern of this substitution. Although most pharmaceuticals were covered under the INSS insurance and could be obtained for free from EMPs, visits to pharmacies did not change with health insurance enrollment, likely reflecting the net effect of substitution away from pharmacies for primary care and increased demand for drugs covered by insurance. ${ }^{20}$ Unfortunately, our data do not allow us to measure the total amount or types of pharmaceuticals used, which would help determine whether the composition or the total value of drug consumption changed in response to the insurance, although the fact that pharmacy visits remained constant suggests that it did not.

In terms of utilization, having health insurance increased the total number of health-care visits by almost one visit per year (0.918), but this was not statistically significant (standard error 0.749 ). There was a similar amount of substitution away from public and private provider visits into free EMP visits

\footnotetext{
${ }^{17}$ The impressive take up of lottery winners who were approached in their booths suggests that this and similar project interventions that target this population may be underestimating the value of their time or the range of factors inhibiting enrollment.

${ }^{18}$ In particular, we measure utilization by asking 'How many times this past year did you visit the each of the following for your health? Private doctor, pharmacy, laboratory, EMP, private hospital/clinic/MINSA health center, and MINSA public hospital'. Results using 'location of treatment of last illness' as a dependent variable are consistent to the main results above. While there may have been heterogeneous treatment effects by illness, we do not observe general patterns of this in the data for last illness.

${ }^{19}$ Note that almost all of the individuals in the analytic sample with insurance were those who had received a 6-month subsidy. The winners of the 2-month subsidy were not interviewed during the follow-up survey.

${ }^{20}$ The survey did not identify the ownership of pharmacies. Most pharmacies are independent private facilities, but respondents may have included some on-site EMP pharmacies within this category.
} 
Table V. Effect of having insurance on health-care utilization and expenditures

\begin{tabular}{|c|c|c|c|c|c|c|}
\hline \multirow[b]{2}{*}{ Panel A: all $(N=2608)$} & \multicolumn{2}{|c|}{ Visited } & \multicolumn{2}{|c|}{ Number of visits } & \multicolumn{2}{|c|}{ Ln (amount spent) } \\
\hline & Coeff. & SE & Coeff. & $\mathrm{SE}$ & Coeff. & $\mathrm{SE}$ \\
\hline Pharmacy & -0.020 & [0.044] & 0.468 & [0.444] & -0.548 & {$[0.344]$} \\
\hline Private doctor & 0.029 & {$[0.038]$} & 0.045 & {$[0.121]$} & 0.222 & {$[0.262]$} \\
\hline Laboratory & -0.067 & {$[0.054]$} & -0.155 & {$[0.208]$} & $-1.072^{* * *}$ & {$[0.365]$} \\
\hline EMP & $0.427^{* * *}$ & {$[0.027]$} & $1.542 * * *$ & {$[0.145]$} & - & - \\
\hline Private clinic/hospital & $-0.089^{*}$ & {$[0.050]$} & $-0.473^{* * *}$ & {$[0.181]$} & -0.565 & {$[0.351]$} \\
\hline Public (MINSA) health center & -0.063 & {$[0.047]$} & $-0.424^{*}$ & {$[0.247]$} & 0.006 & {$[0.028]$} \\
\hline Public (MINSA) hospital & $-0.115^{* * *}$ & {$[0.040]$} & -0.176 & {$[0.152]$} & -0.025 & {$[0.021]$} \\
\hline \multirow[t]{2}{*}{ All/any } & -0.001 & {$[0.034]$} & 0.918 & {$[0.749]$} & -0.522 & {$[0.343]$} \\
\hline & \multicolumn{2}{|c|}{ Visited } & \multicolumn{2}{|c|}{ Number of visits } & \multicolumn{2}{|c|}{ Ln (amount spent) } \\
\hline Panel B: MFI clients $(N=1013)$ & Coeff. & $\mathrm{SE}$ & Coeff. & $\mathrm{SE}$ & Coeff. & SE \\
\hline Pharmacy & -0.018 & {$[0.064]$} & 0.653 & {$[0.726]$} & -0.646 & {$[0.508]$} \\
\hline Private doctor & 0.019 & {$[0.058]$} & -0.016 & {$[0.170]$} & 0.004 & {$[0.394]$} \\
\hline Laboratory & -0.119 & {$[0.081]$} & -0.142 & {$[0.377]$} & $-1.130 * *$ & {$[0.544]$} \\
\hline EMP & $0.440^{* * *}$ & {$[0.040]$} & $1.786^{* * *}$ & {$[0.240]$} & - & - \\
\hline Private clinic/hospital & -0.082 & {$[0.074]$} & $-0.658^{* *}$ & {$[0.269]$} & -0.567 & {$[0.512]$} \\
\hline Public (MINSA) health center & -0.054 & {$[0.069]$} & -0.433 & [0.298] & 0.028 & {$[0.028]$} \\
\hline Public (MINSA) hospital & $-0.152^{* *}$ & {$[0.060]$} & -0.262 & {$[0.255]$} & -0.046 & {$[0.033]$} \\
\hline \multirow[t]{2}{*}{ All/any } & 0.006 & {$[0.046]$} & 1.118 & {$[1.228]$} & -0.719 & {$[0.490]$} \\
\hline & \multicolumn{2}{|c|}{ Visited } & \multicolumn{2}{|c|}{ Number of visits } & \multicolumn{2}{|c|}{ Ln (amount spent) } \\
\hline Panel C: non-MFI clients $(N=1595)$ & Coeff. & SE & Coeff. & SE & Coeff. & SE \\
\hline Pharmacy & -0.026 & [0.059] & 0.353 & {$[0.559]$} & -0.471 & {$[0.464]$} \\
\hline Private doctor & 0.014 & {$[0.051]$} & 0.045 & {$[0.166]$} & 0.265 & {$[0.351]$} \\
\hline Laboratory & -0.032 & [0.072] & -0.13 & {$[0.226]$} & $-1.040^{* *}$ & {$[0.491]$} \\
\hline EMP & $0.422^{* * *}$ & {$[0.037]$} & $1.364^{* * *}$ & {$[0.175]$} & - & - \\
\hline Private clinic/hospital & -0.106 & {$[0.067]$} & -0.374 & {$[0.249]$} & -0.621 & {$[0.479]$} \\
\hline Public (MINSA) health center & -0.07 & {$[0.064]$} & -0.468 & {$[0.393]$} & -0.011 & {$[0.044]$} \\
\hline Public (MINSA) hospital & -0.082 & {$[0.055]$} & -0.101 & {$[0.186]$} & -0.009 & {$[0.029]$} \\
\hline All/any & -0.002 & {$[0.048]$} & 0.721 & {$[0.946]$} & -0.384 & {$[0.475]$} \\
\hline
\end{tabular}

Notes: This table presented the impact of having health insurance on having visited each health provider, the number of visits to that health provider (unconditional on any visit), and the log expenditures at that provider (unconditional on any visit) at the follow-up survey. Having insurance is instrumented with being offered a 6-month subsidy to affiliate at the INSS or at an MFI and is equivalent to the specifications in Table $\mathrm{V}$; controls for the baseline visits or expenditures are also included. Each coefficient is from a separate regression and standard errors are in brackets. ${ }^{*}$ Significant at $10 \% ;{ }^{* *}$ significant at $5 \%$; ${ }^{* *}$ significant at $1 \%$.

(both annually and for last illness - results not shown). For MFI and non-MFI clients, the patterns are quite similar: visits to the EMP increase, with a decrease in the use of private and public health facilities.

Health expenditure patterns mirror the changes in utilization patterns. Enrolling in health insurance led to a $55 \%$ decline in total OOP expenditures for respondents, although this is not statistically significant (standard error of 0.344), with the largest expenditure reductions for private clinics (particularly among non-MFI clients), laboratories, and pharmacies. As services from pharmacies and laboratories often account for the largest and most frequent OOP expenses among uninsured informal sector workers, these services are the most valuable categories of care covered by INSS. It should be noted, however, that, just as with baseline health expenditures, total health expenditures between baseline and follow-up fell below the average annual insurance premium. Hence, insurance did not provide an absolute cost savings for the average individual. ${ }^{21}$ However, for risk-averse individuals, an

\footnotetext{
${ }^{21}$ Note that an actuarially fair health insurance plan would not result in absolute costs savings to the average member.
} 
important component of the value of insurance is having coverage in cases of large unanticipated health shocks, a benefit that accrues to all those covered regardless of utilization. Unfortunately, our sample is too small and period of coverage too short to observe enough large health shocks and therefore measure the benefit to individuals of being covered in such events in terms of avoiding foregone care, sale of productive assets, or entry into debt.

\subsection{Effect of insurance: family planning and other services}

An additional outcome of interest in this analysis was the association between insurance enrollment and utilization of reproductive health and family planning (RH/FP) services, especially at INSS-contracted EMP facilities. At baseline, $74.8 \%$ of the respondents had been sexually active in the previous 6 months and 75.4 of those (or $64 \%$ of the total sample) were using some form of birth control. We witnessed no difference in use over time between those who enrolled in insurance and those who did not, and no significant change in use of EMPs as a source of FP (results not shown). Similarly, insurance coverage did not significantly increase the likelihood of using RH services (defined to include antenatal care, delivery in a health facility, or receipt of RH screening tests; results not shown).

Among the 220 individuals in the sample who had been pregnant or had a pregnant partner in the 12 months before the follow-up survey, we found no significant differences between insured and noninsured on the likelihood of receiving prenatal care, receiving multivitamins, or having an ultrasound, although rates of these services were already high. However, insured women were more likely to receive prenatal attention from EMPs $(28 \%$ of the insured individuals versus $7 \%$ of the uninsured), suggesting a potential improvement in quality of care. In addition, insured women were more likely to have had their babies at an $\operatorname{EMP~(28\% ~of~the~insured~versus~} 8 \%$ of the uninsured). These statistics should be viewed with caution given the small sample size of women who were pregnant or who had a birth. We found no impact of being insured on the utilization of preventive tests (such as pap smears, prostate exams, mammograms, HIV tests, colonoscopy, vision, hearing, dental exams, blood pressure, overall checkups, pregnancy tests, or malaria tests), nor on the likelihood of hospitalization (results not shown).

Finally, we found no significant effects on any measures of health status including any type of sickness such as flu, fever, diarrhea, or on measures of length of time sick - for example, the number of days of missed work the last time the respondent was ill. This is consistent with finding no significant effect of being insured on the likelihood of receiving shots or antibiotics at the time of last illness. We also found no significant effect of being insured on perceived health or perceived life expectancy (results not shown). The absence of an effect of insurance coverage on health status suggests that quality of care did not significantly improve as a result of shifting from public and private health-care providers to EMP clinics, although it is important to note that the period of study is very short for observing changes in crude measures of health status.

Overall, the most striking finding from this analysis is that the health insurance coverage did not appear to substantially change health-care utilization and, as a result, had little impact on health. Unfortunately, our data do not permit us to assess and compare the total value of health-care services consumed over the period for the insured and uninsured, but the health-care utilization and health outcomes data show little difference between the insured and the uninsured in number of visits/tests/hospitalizations or health status measures, suggesting the quality of care was unchanged. The absence of an increase in health-care consumption in response to the insurance suggests both that moral hazard is not an important feature of behavior in this segment of the market and that upfront payments do not pose a major barrier to health-care utilization among this population, for instance, due to liquidity constraints. This result has important implications for the affordability of health insurance schemes targeted to similar subpopulations. For instance, the result provides evidence 
Table VI. Determinants of insurance retention

\begin{tabular}{|c|c|c|c|c|}
\hline \multirow{2}{*}{$\begin{array}{l}\text { Dependent variable: still enrolled in insurance } \\
\text { program at follow up }(0 / 1)\end{array}$} & \multicolumn{2}{|c|}{ All } & \multirow{2}{*}{$\frac{\text { MFI client }}{\text { (3) }}$} & \multirow{2}{*}{$\begin{array}{c}\text { Non-MFI client } \\
\text { (4) }\end{array}$} \\
\hline & (1) & (2) & & \\
\hline Information & $\begin{array}{l}-0.828 * * * \\
{[0.089]}\end{array}$ & $\begin{array}{l}-0.851^{* * *} \\
{[0.102]}\end{array}$ & & \\
\hline Six-month subsidy - INSS & $\begin{array}{l}{[0.009]} \\
-0.906^{* * *} \\
{[0.045]}\end{array}$ & $\begin{array}{l}-0.927^{* * *} \\
{[0.069]}\end{array}$ & & \\
\hline Six-month subsidy - MFI & $\begin{array}{l}-0.890^{* * *} \\
{[0.049]}\end{array}$ & $\begin{array}{l}-0.925^{* * *} \\
{[0.070]}\end{array}$ & $\begin{array}{c}0.044 \\
{[0.043]}\end{array}$ & $\begin{array}{c}-0.022 \\
{[0.032]}\end{array}$ \\
\hline Male & $\begin{array}{c}-0.013 \\
{[0.027]}\end{array}$ & $\begin{array}{c}0.008 \\
{[0.030]}\end{array}$ & $\begin{array}{l}-0.100^{* *} \\
{[0.051]}\end{array}$ & $\begin{array}{l}0.034 \\
{[0.035]}\end{array}$ \\
\hline Years of education & {$\left[0.0031^{* * *}\right.$} & {$\left[0.009^{* *}\right.$} & $\begin{array}{l}0.016^{* * *} \\
{[0.006]}\end{array}$ & $\begin{array}{c}0.004 \\
{[0.005]}\end{array}$ \\
\hline Married & $\begin{array}{l}0.03 \\
{[0.026]}\end{array}$ & $\begin{array}{l}0.035 \\
{[0.028]}\end{array}$ & $\begin{array}{c}0.021 \\
{[0.045]}\end{array}$ & $\begin{array}{c}0.035 \\
{[0.035]}\end{array}$ \\
\hline MFI client & $\begin{array}{c}0.018 \\
{[0.026]}\end{array}$ & $\begin{array}{c}-0.004 \\
{[0.028]}\end{array}$ & & \\
\hline Number of children & $\begin{array}{c}-0.006 \\
{[0.012]}\end{array}$ & $\begin{array}{l}-0.006 \\
{[0.012]}\end{array}$ & $\begin{array}{l}-0.01 \\
{[0.021]}\end{array}$ & $\begin{array}{r}-0.003 \\
{[0.016]}\end{array}$ \\
\hline Has children under 12 & $\begin{array}{c}-0.019 \\
{[0.031]}\end{array}$ & $\begin{array}{c}-0.004 \\
{[0.035]}\end{array}$ & $\begin{array}{c}0.014 \\
{[0.053]}\end{array}$ & $\begin{array}{c}-0.032 \\
{[0.044]}\end{array}$ \\
\hline Log income & & $\begin{array}{c}-0.008 \\
{[0.016]}\end{array}$ & $\begin{array}{c}0.021 \\
{[0.023]}\end{array}$ & $\begin{array}{c}-0.001 \\
{[0.024]}\end{array}$ \\
\hline Has any savings & & $\begin{array}{l}0.024 \\
{[0.029]}\end{array}$ & $\begin{array}{l}-0.05 \\
{[0.042]}\end{array}$ & $\begin{array}{c}0.039 \\
{[0.040]}\end{array}$ \\
\hline Smokes & & $\begin{array}{l}-0.037 \\
{[0.036]}\end{array}$ & $\begin{array}{c}0.081 \\
{[0.078]}\end{array}$ & $\begin{array}{c}-0.058 \\
{[0.039]}\end{array}$ \\
\hline Any chronic disease & & $\begin{array}{c}-0.033 \\
{[0.029]}\end{array}$ & & \\
\hline Ever sick & & $\begin{array}{c}-0.001 \\
{[0.040]}\end{array}$ & & \\
\hline Log costs of health care & & $\begin{array}{c}0.000^{*} \\
{[0.000]}\end{array}$ & & \\
\hline Number of visits to provider & & $\begin{array}{c}0.001 \\
{[0.002]}\end{array}$ & & \\
\hline Any visit to provider & & $\begin{array}{c}0.042 \\
{[0.040]}\end{array}$ & & \\
\hline $\begin{array}{l}\text { Observations } \\
R^{2}\end{array}$ & $\begin{array}{l}530 \\
0.07\end{array}$ & $\begin{array}{l}470 \\
0.1\end{array}$ & $\begin{array}{c}185 \\
0.14\end{array}$ & $\begin{array}{l}269 \\
0.05\end{array}$ \\
\hline
\end{tabular}

Notes: This table presented the determinants of retention among those who enrolled in the health insurance. Columns 3 and 4 consist of only those who received a 6 -month subsidy. ${ }^{*}$ Significant at $10 \% ;{ }^{* *}$ significant at $5 \%$; ${ }^{* *}$ significant at $1 \%$.

that copayments are not important for preventing 'overconsumption' of health care among the insured. ${ }^{22}$

\subsection{Retention}

Consistent with the absence of a perceived benefit to health insurance among those on the margin of enrolling, retention rates in the program were very low after the expiration of the subsidy. At the followup survey, less than $10 \%$ of those who had enrolled in the previous year were still paying for insurance. Table VI presents OLS regressions predicting retention rates among those who had enrolled for

\footnotetext{
${ }^{22}$ While overall effects on health due to the insurance would be of interest, the research design was initially powered to detect significant effects on health utilization and expenditures, not particular health outcomes. This is mainly due to the short time frame of the study as well as the relatively low take-up rates reducing the power of the first stage (see, for example, Gideon et al. 2007).
} 
insurance. Not surprisingly, the results suggest that those receiving the largest subsidies to sign up for insurance were least likely to be retained over time; however, the differences in retention are not statistically significant (not shown). Other baseline measures of health-care cost had no significant impact on the likelihood of remaining insured (Column 2). Smokers and those who had any chronic or recurring disease were less likely to continue on the plan (although this is not statistically significant).

We find the same general pattern of determinants of retention comparing MFI clients and non-MFI clients. Given the small sample size of those who purchased insurance (especially, for example, among those receiving the informational brochure only), we restrict the sample to those offered 6-month subsidies (columns 3 and 4) to test whether there were differences in retention by assignment to enroll at MFIs or at the INSS. MFI clients assigned to affiliate at an MFI branch were 4.4 percentage points more likely to remain insured (column 4) than those assigned to affiliate at the INSS, although the difference is not statistically significant. While this is suggestive of the convenience of MFIs as payment channels, it is important to note that, while place of enrollment was randomized, the above estimates are conditional on having purchased insurance, which is endogenous.

The patterns of retention in the program are arguably some of the most striking finding of the study and have important implications for the feasibility of creating sustainable health insurance programs for informal sector workers through voluntary schemes. If few people remain in the program, or if those that remain are the most sick, the program will neither be effective in reaching the bulk of the uninsured nor sustainable from a cost perspective for the few that are reached. And while low enrollment rates may improve over time as information about the program spreads, low retention rates may be a much more a fundamental indicator of program failure. Very low retention speaks to basic flaws in the program's design that would need to be changed to make the program viable. For instance, the program may have to increase the number and quality of providers or change the pay structure to a system with lower premiums and higher copayments.

\section{CONTEXTUAL CONSIDERATIONS}

To better understand our findings, we conducted a series of individual interviews and focus group discussions to learn more about informal sector workers' experiences with the INSS insurance. First, to gain insight into reasons for nonenrollment, we conducted individual interviews with 40 randomly selected Huembes market vendors who had won subsidies but not enrolled. To better understand whether participating EMPs were meeting the standards necessary to attract and retain subscribers and providing appropriate services to the informal sector, we also interviewed 20 participants who had enrolled.

In total, we conducted nine focus group discussions among five strata of participants defined according to MFI client status, receipt of a subsidy, and enrollment in the insurance:

\begin{tabular}{lccc}
\hline & \multicolumn{2}{c}{ Won subsidy } & No subsidy \\
\cline { 2 - 3 } & Enrolled & Did not enroll & Did not enroll \\
\hline MFI client & Stratum 1 & Stratum 3 & Stratum 5 \\
Non-MFI client & Stratum 2 & Stratum 4 & \\
\hline
\end{tabular}


With the exception of stratum 5, two focus group discussions were organized for each stratum, one each with vendors from the Oriental and Huembes markets. ${ }^{23}$ In total, 73 market vendors participated in the discussions. Selected qualitative findings, grouped by theme, are discussed below. In addition to these focus groups, we also conducted interviews with MFI representatives.

Time and convenience costs: Interviews with the 40 randomly selected vendors in the Huembes market who had not purchased insurance even after winning a 6-month subsidy revealed that 25 intended to enroll. Half of these explained they had not found the time to do so. Other reasons for not signing up included problems obtaining all of the required documentation (photos, copy of ID card, children's birth certificates, and subscription forms) and confusion about the enrollment process.

Information: Few participants in our focus group discussions had heard of the INSS insurance program for informal workers prior to the baseline survey. In the focus groups, some expressed confusion about the insurance benefits; in particular, some participants thought that the insurance provided benefits during old age. This confusion may have been related to the fact that INSS formal sector coverage bundles pension, health insurance, and worker's compensation into one package. Discussants also noted difficulties obtaining clear information about the program, particularly from the MFIs; 12 MFI clients said that they received no information about the program from their MFI. A few were skeptical of the program and its legitimacy, and worried that they might get 'trapped' into paying for the insurance after the subsidy expired. The key recommendations suggested by participants for improving the program were better provision of information about what benefits were covered, how to enroll, what fees would be charged, and how to make payments.

'I think that is the reason that most people don't pay into the insurance, we don't know where to do it or with whom to do it. I think there needs to be more publicity ...' - MFI client who won a subsidy but did not enroll [Huembes market]

Eight participants reported that they never received proof of their enrollment in the insurance from INSS. This led to confusion about whether the program was 'real,' whether they were indeed covered, and when they could start using services. ${ }^{24}$

'I was told that ... they would notify me when I could use the insurance, a thing that never happened.

After a week passed, then two weeks, I said that it was a real joke because they never notified me.

Then 8 months later, a statement arrived that owed two months of insurance payments.' - Non-MFI client who enrolled [Oriental market]

Attitudes toward MFIs as insurance intermediaries: In contrast to researchers' expectations, focus group discussants expressed a preference for enrolling in the insurance directly with INSS rather than through MFIs. INSS was perceived as a more stable institution, whereas MFIs were potentially

\footnotetext{
${ }^{23}$ Respondents who had provided telephone numbers during the follow-up survey were selected randomly within each stratum. Researchers first contacted potential participants via telephone, and followed up with an in-person visit to the market stall to administer an informed consent protocol to those who agreed to participate. Despite confirming their consent to participate, some did not attend. Only 2 out of 30 recruited Stratum 5 participants in the Oriental market showed up as planned, so that discussion was cancelled. Focus group discussions were held at quiet locations near each market. All participants were paid a transportation stipend of approximately 5 dollars. A professional facilitator recruited the participants and moderated each discussion. All discussions were tape recorded and transcribed.

${ }^{24}$ Another potential source of confusion about enrollment derived from the failure of INSS to deliver monthly billing statements. Under the traditional INSS (formal sector) insurance scheme, couriers on motorbikes hand-deliver monthly statements to each employer's office; this system was administratively burdensome for the dispersed informal sector workers. While some workers received their statements, this was not always reliable and this may have caused more confusion.
} 
vulnerable to bankruptcy and possibly less trustworthy. Respondents noted that health insurance was the regular 'business' of INSS, whereas MFIs were not experts in health insurance:

'INSS knows the benefits, what's not covered, while the MFI is a lending institution and doesn't understand [health]. Health is not its specialty; its thing is money.'

- MFI client that enrolled [Oriental market]

Several discussants expressed concern that MFIs might charge hidden fees or interest for providing insurance services. However, a handful of participants expressed a preference to make routine payments at banks and MFIs, noting the long waiting lines at the INSS office.

One possible reason for poor service among the MFIs was conflict with the government over their role in the program. As described earlier, approximately 10 months into the program, INSS chose not to renew their contracts with the participating MFIs. While the MFIs were engaged during the first phase of the pilot and evaluation, once it became clear that INSS contracts with MFIs would not be renewed, MFIs halted their efforts to market the voluntary program and discontinued offering payment services on behalf of INSS. The change in the process, and the accompanying lack of information, was likely to have been a source of confusion among participants who had signed up with an MFI. In the follow-up survey, $62 \%$ of participants claimed they did not know where to make insurance payments.

Role of EMPs: The individual interviews with 20 selected survey participants who had registered for insurance indicated that a small number of EMP clinics were aggressively encouraging subsidy winners to enroll in the insurance and register with their clinic. Indeed, two small EMPs had over $40 \%$ of the market share. However, enrollees reported that these EMPs did not provide sufficient information on when they could begin to utilize services, and they expressed widespread dissatisfaction with the clinics' customer service and willingness to serve clients under the new insurance scheme. Hence, a key factor in improving retention may be increasing provider quality of care and level of service.

Willingness to pay for insurance: Although many focus group participants reported that health insurance was worth buying, almost all indicated a preference for an insurance product with a lower price tag. Those who enrolled and had young children indicated that obtaining coverage for their children under 12 was a key motivating factor. Other reported reasons for enrollment were ensuring access to regular medical checkups and getting protection in the case of future emergencies or surgeries. Reasons for nonenrollment, cited by those who received a subsidy but did not purchase the insurance, included the following: having children who were too old to be eligible; preference to visit a pharmacy rather than a doctor for most health care because it was faster and more convenient; concern that the premium was too high to afford after the subsidy expired; and the time costs and inconvenience associated with the enrollment process. Given this, an important design consideration may be copayment versus flat fee for service.

MFI participation: Regarding involvement of MFIs in voluntary health insurance schemes for the poor, the challenges of a program fundamentally based on a public-private partnership cannot be underestimated. First, it is challenging to coordinate programs between institutions that have substantial differences in culture, management styles, and processes. These differences can lead to miscommunication and frustration among personnel on both sides and require significant coordination, transparency, and commitment from senior management. Second, a lack of trust between INSS and the MFIs about incentives for participating in the program tainted the partnership. INSS's suspicion that MFIs would unfairly profit from the program appears to have been unfounded, according to our interviews with MFIs. The initial investment by MFIs in operations, training, and marketing for the program were significant, and low volumes of sales meant that MFIs recovered few of their costs. INSS argued that MFIs would gain financially by having healthier clients who then repaid their loans more steadily, but given MFIs' already very high loan repayment rates, this potential benefit was rather insignificant. 
MFIs did have incentives to participate in the program, however. According to our interviews with MFI representatives, they saw the INSS insurance as a marketable complement to their existing credit services. Strong competition in the microfinance sector in Nicaragua drives MFIs to seek new products that would give them a competitive advantage. In addition, the MFIs' sense of social mission played an important role in their decision to participate. MFIs were aware that their clients lacked access to quality health care and saw the INSS product as a cost-effective solution to improve this access. The incentives faced by individual MFI staff members to support the demonstration project, however, were less clear. Loan officers who were charged with selling the product found that closing a 'sale' of insurance could take two visits and over an hour.

\section{CONCLUSIONS}

This article presents the results from a randomized evaluation of the Nicaraguan government's 2007 pilot program to extend social security health insurance to the informal sector on a voluntary basis. We find overall, low rates of enrollment. Those who did enroll substituted toward services at covered facilities and total OOP expenditures fell. We find no evidence of an increase in health-care utilization among the newly insured. These main findings are similar to analysis of Mexico's voluntary insurance program (King et al., 2009), although our analysis sheds light on the effectiveness of some elements of the program's design in terms of encouraging enrollment and retention and the program's effects on health service utilization and expenditures. Our results provide important evidence on the challenges of providing health insurance coverage to informal sector workers in developing countries through the extension of an existing mandatory public sector program to a population for whom enrollment is voluntary.

Ultimately, while the INSS program aimed at providing greater accessibility to informal sector workers by bringing the enrollment and payments processes closer to the physical location of these workers (via MFIs), results from this study indicate that the Nicaraguan government did not succeed in creating a sustainable health insurance program, largely because convenience and quality of care were not adequately addressed. We emphasize six central policy-relevant conclusions based on our findings.

First, if individuals are risk averse, they should be willing to pay at least as much for insurance premiums as their anticipated annual health expenditures on services that would be covered by the insurance. At the baseline, $11 \%$ of informal market vendors in Managua who did not enroll in the insurance program had higher baseline annual health expenditures than the annual cost of flat fee (no co-payments) insurance coverage. The program was designed in order to increase quality services and reduce wait-times. However, focus group discussions suggest that both factors - utilization costs and quality concerns - were important. Low willingness to pay suggests that the average individual assigns little value to insurance as a means of managing financial risk, that is, he/she is not willing to pay premiums much beyond what he/she expects to use over the course of the year. The price of the insurance product may have indeed been too high; we do not know from our data to what extent demand may have been greater at lower prices.

Second, although lowering the price of insurance through subsidies encouraged enrollment, very few of subscribers on the margin of influence were willing to pay the full price of insurance once the subsidy ran out, indicating that short-term price subsidies were not an effective means of promoting insurance enrollment in the informal sector. The lower initial price was designed to increase demand for insurance among the previously uninsured. However, in this setting it appears that permanently lower prices (or higher quality services) are needed to sustain a voluntary program. This is important evidence on the limitations of using subsidies as a means of attracting new insurance customers. Instead, governments should consider alternative payment structures, such as lowering premiums and introducing copayments, to increase demand for the product. Furthermore, the low cost of private and public sector 
providers sought out by the uninsured - which kept OOP health-care costs below the cost of INSS insurance premiums - suggests that respondents are combining available services more efficiently than the INSS. Further analysis might evaluate the quality of the services being used and determine whether a more efficient 'package' can be offered by the INSS or other insurers.

Third, streamlined enrollment procedures by offering on-site affiliation were valuable in attracting new customers, indicating that time costs were important for Nicaraguan informal sector workers' decisions around health insurance. This is similar to other work in other developing countries, which suggests that transaction costs are important for insurance enrollment and health-care utilization (Pauly et al., 2008, 2006). Similar strategies may be necessary for launching a new health insurance program in a comparable setting, both to bring the program to scale and broaden the risk pool. Our surveys and focus group discussions indicated a strong preference for a more transparent and convenient registration process. Time constraints were cited as an important reason for not enrolling in the insurance, even when it was subsidized. Participants also criticized slow, ineffective distribution of billing statements. Further research might test the potential for automated registration procedures through PDAs and other remote devices, as well as paperless billing through mechanisms such as SMS messages on cell phones. Payment systems themselves could potentially bypass the MFI or bank if sufficient technology is integrated into the process. Confusion about the location of payments and billing problems also affected the retention of survey respondents who signed up for insurance.

Fourth, our results suggest that insurance coverage did not encourage overconsumption of healthcare services. Contrary to what many governments fear when introducing flat-fee health insurance coverage, those who enrolled in the program did not exhibit a significantly different pattern of healthcare utilization than they did when they were uninsured. While we cannot completely rule out the possibility that the insured increase their consumption of health care conditional on need, particularly given that that we do not have very precise measures of quality, the change in consumption is certainly not significant enough to destabilize an insurance program.

Fifth, while using MFIs as delivery channels may be useful when government programs have limited outreach and infrastructure and when MFIs view mutual benefit in the association, offering transactions services through MFIs is not sufficient to bring workers in the door. Hence, it is important not to underestimate the complexity involved in working with MFIs. Suspicion about possible profit-oriented motivations of MFIs in Nicaragua damaged the tone of their working relationship with INSS. Strong strategic leadership and commitment are needed within both sectors to ensure that the operational arrangements are clear and incentives are well aligned. Finally, administrative procedures for both enrollment and premium payments need to be clearly delineated and convenient for users.

Sixth, the theory that the INSS health insurance for informal sector workers would lessen the burden on Ministry of Health resources may not have been founded. At baseline, informal sector workers in our sample were already more likely to use private sector providers than public providers. Enrolling in INSS health insurance resulted in significant switching out of use of both public and private facilities into EMP services. Programs seeking to reduce the burden on public sector resources of public health facilities should consider that informal sector workers in Nicaragua spend significantly more out of pocket on health care than the overall population and may not be among those placing the greatest burden on public resources. Segmentation of the informal sector may identify workers in the lower income brackets most likely to use public sector resources and perhaps able to pay smaller premiums for complementary insurance or for basic pre-paid private service packages in convenient locations. For those informal sector workers on the higher end of the income spectrum, who are already using private health facilities and pharmacies, insurance programs need to take great care to differentiate themselves in terms of price, convenience, and quality in order to ensure retention.

In sum, to ensure retention in an unsubsidized insurance program, benefit packages must be designed to balance informal workers' preference for convenience and quality of care with their limited 
disposable income. Qualitative findings indicate that respondents wanted convenient care that covered young children and provided insurance for costly services such as emergencies and surgery. Quantitative results show a preference for private providers, particularly among MFI clients. While drug coverage was an appealing component of the insurance, it adds significantly to its cost. Rather than offering insurance-based drug coverage, OOP expenses for pharmaceuticals could be reduced through efforts to promote generic drug usage and pharmacy discounts. Education about the specific coverage and value of insurance as a risk mitigation tool may also help increase the willingness of informal sector workers to pay for insurance, as they may not fully understand the risk management value of coverage for catastrophic care. Voluntary insurance programs have the potential to contribute to health financing in developing countries; given the low take-up rate in this study, it is difficult to generalize the overall lack of success to other countries and contexts. It would be useful for researchers to study the effects of insurance over longer periods of time to further understand long-run impacts, as well as the effects of an insurance product after logistical and management challenges have been worked out.

\section{ACKNOWLEDGEMENTS}

Thornton contributed to the evaluation design and quantitative analyses; Hatt conducted qualitative analysis, and contributed to the follow-up study analysis; Field contributed to the evaluation design and quantitative analyses; Islam contributed to the evaluation design; Solís was responsible for data collection; and González contributed to the article. Funding for this study was provided by USAID's Private Sector Partnerships-One (PSP-One) project and the Global Development Network (GDN). The authors' views expressed here do not necessarily reflect the views of the United States Agency for International Development or the United States Government. The evaluation was coordinated for GDN by EA Consultants. The evaluation team would like to acknowledge the extensive contributions of the field team at ALVA Consultores including Dr Ana del Carmen Rojas and Ms Rosario Duarte, as well as the project coordination and support of Barbara Magnoni, EA Consultants, and the contributions in the project design of Tania Dmytraczenko, the World Bank. We are grateful for helpful comments and suggestions from Robert Lalonde, Jeff Smith, and other GDN mentors and participants as well as participants at Harvard School of Public Health, the World Bank Research Group, the Population Association of Iran, and the Population Association of America seminars. We also thank research assistance from Anne Fitzpatrick. This study met approval at Institutional Review Boards at Abt Associates, the University of Michigan, and ALVA (Nicaragua).

\section{CONFLICTS OF INTERESTS}

No conflicts of interests disclosed.

\section{APPENDIX A: TIMELINE}

\begin{tabular}{lll}
\hline 2007 & January & Government provision of health insurance \\
& to informal sector workers \\
& March/April & Round one baseline surveys \\
June/July & Round two baseline surveys \\
July & In-depth interviews \\
August-December & Collection of insurance affiliation data \\
September & In-depth interviews \\
& October & No renewal of MFI/INSS contract \\
& April-June & Follow-up surveys \\
& September/October & Focus group discussions \\
\hline
\end{tabular}




\section{APPENDIX B: SAMPLE AND RANDOM ASSIGNMENT}

\begin{tabular}{|c|c|c|}
\hline Panel A: Completion rates of baseline survey & Number & Percent $(\%)$ \\
\hline \multicolumn{3}{|l|}{ Round 1} \\
\hline Away & 139 & 7 \\
\hline Refused & 114 & 6 \\
\hline Not eligible & 123 & 7 \\
\hline Other & 87 & 5 \\
\hline Completed & 482 & 51 \\
\hline Total & 945 & \\
\hline \multicolumn{3}{|l|}{ Round 2} \\
\hline Away & 1073 & 24 \\
\hline Refused & 310 & 7 \\
\hline Not eligible & 707 & 16 \\
\hline Other & 54 & 1 \\
\hline Completed & 2386 & 53 \\
\hline Total & 4530 & \\
\hline Panel B: Completion rates of the follow-up survey & Number & Percent $(\%)$ \\
\hline Moved/Temporarily away & 26 & 1 \\
\hline Deceased, Hospitalized, Other & 19 & 0.7 \\
\hline Refused & 152 & 5 \\
\hline Completed & 2610 & 93 \\
\hline Total Approached & 2807 & \\
\hline
\end{tabular}

Notes: Panel A includes all of those who were in Oriental Market, Huembes, and Ivan Montenegro who were eligible for the follow-up survey. Out of the 2868 who were interviewed at baseline, 2807 were approached at the follow-up.

APPENDIX C: RANDOM ASSIGNMENT

\begin{tabular}{|c|c|c|c|}
\hline & Number & Percent $(\%)$ & $\begin{array}{l}\text { Percent interviewed } \\
\text { at follow up }(\%)\end{array}$ \\
\hline Pure control & 119 & 4 & 93 \\
\hline Informational brochure only & 1200 & 43 & 93 \\
\hline Six-month subsidy, enroll at INSS & 758 & 27 & 94 \\
\hline Six-month subsidy, enroll at MFI & 730 & 26 & 92 \\
\hline Total & 2807 & & 93 \\
\hline
\end{tabular}

Notes: This table includes 2807 individuals who were approached for the follow-up survey. The 6-month subsidy was worth approximately 96 dollars.

\section{APPENDIX D: BASELINE CHARACTERISTICS BY TREATMENT STATUS}

\begin{tabular}{lccccc}
\hline & Control & Info only & Six-month - INSS & Six-month - MFI & $\begin{array}{c}F \text {-test of joint significance } \\
(p \text {-value })\end{array}$ \\
\cline { 2 - 5 } & $(1)$ & $(2)$ & $(3)$ & $(4)$ & $(5)$ \\
\hline Age & 38.5 & 37.5 & 38.1 & 37.8 & 0.35 \\
Male & 0.38 & 0.34 & 0.36 & 9.3 & 0.61 \\
Years of education & 8.6 & 9.3 & 9.2 & 0.68 & 0.31 \\
Married & 0.78 & 0.71 & 0.69 & 2.0 & 0.12 \\
Number of children & 2.2 & 2.0 & 0.1 & 0.15 & 0.24 \\
Smokes & 0.18 & 0.16 & 0.14 & 267.1 & 0.51 \\
Monthly income & 287.0 & 256.8 & 304.7 & 0.38 & 0.10 \\
MFI client & 0.50 & 0.39 & 0.37 & 674 & 0.10 \\
Observations & 111 & 1112 & 711 & & \\
\hline
\end{tabular}

Notes: This table presents baseline statistics by randomized treatment status for 2608 respondents. Column 5 presents the $p$-value of a joint test of significance of equality of coefficients of a regression of each dependent variable on indicators of being in each treatment arm. 


\section{REFERENCES}

Abel-Smith B. 1992. Health insurance in developing countries: lessons from experience. Health Policy and Planning 7(3): 215-226.

Alderman H, Paxson C. 1994. Do the poor insure? A synthesis of the literature on risk sharing institutions in developing countries. Economics in a Changing World: Proceedings of the Tenth World Congress of the International Economic Association. Macmillan Press: Moscow, London.

Barros R. 2009. Wealthier but not much healthier: effects of a health insurance program for the poor in Mexico. Stanford University, Working Paper.

Behrman J, Knowles J. 1999. The Demand for Health Insurance in Vietnam. Mimeo.

Chankova S, Sulzbach S, Diop F. 2008. Impact of mutual health organizations: evidence from West Africa. Health Policy and Planning 23(4): 264-276.

Churchill C. 2003. Insurance work for microfinance institutions: a technical guide to developing and delivering microinsurance. Focus Programme for Small Enterprise Development. International Labour Organization: Geneva.

Churchill C, Cohen M. 2006. Marketing microinsurance. In Protecting the Poor, A Microinsurance Compendium, Churchill C (ed.). International Labor Organization: Geneva.

Dercon S. 2002. Income risk, coping strategies and safety nets. The World Bank Research Observer 17(2): $141-166$.

Dercon S, Kirchberger M, Gunning JW, Platteau J. 2008. Literature review on microinsurance. European Development Research Network $(E U D N)$. Oxford University.

Duflo E, Banerjee A, Deaton A. 2004. Wealth, health, and health services in rural Rajasthan. American Economic Review Papers and Proceedings 94(2): 326-330.

Dow W, Schmeer K. 2003. Health insurance and child mortality in Costa Rica. Social Science and Medicine 57(6): 975-986.

Fafchamps M. 1999. Risk Sharing and Quasi-credit. The Journal of International Trade and Economic Development 8(3): 257-278.

Franco L, Diop F, Burgert C, Kelley A, Makinen M, Simpara C. 2008. Effects of mutual health organizations on use of priority health-care services in urban and rural Mali: a case-control study. Bulletin of the World Health Organization 86(11): 830-838.

Gakidou E et al. 2006. Assessing the effect of the 2001-2006 Mexican health reform: an interim report card. The Lancet 368: 1920-1935.

Gertler P, Gruber J. 2002. Insuring consumption against illness. American Economic Review 92(1): 5176.

Gertler P, Solon O. 2002. Who benefits from social health insurance? Evidence from the Philippines. Unpublished Manuscript, University of California, Berkeley and the University of the Philippines.

Giedion U et al. 2007. The impact of subsidized health insurance on access, utilization and health status in Colombia. iHEA 2007 6th World Congress: Explorations in Health Economics Paper. Available at SSRN: http:// ssrn.com/abstract $=993919$.

Gine X, Tonsend RM, Vickery J. 2007. Patterns of rainfall insurance participation in rural India. Policy Research Working Paper Series 4408, The World Bank.

GTZ, ILO, WHO. 2005. Recommendations for action. The International Conference on Social Health Insurance in Developing Countries. GTZ, ILO, and WHO: Geneva.

Gumber A, Kulkarni V. 2000. Health insurance for informal sector: case study of Gujarat. Economic and Political Weekly, Septermber 30.

Jack W. 2003. Contracting for health services: an evaluation of recent reforms in Nicaragua. Health Policy and Planning 18(2): 195-204.

Jowett M. 2003. Do informal risk sharing networks crowd out public voluntary health insurance? Evidence from Vietnam. Applied Economics 35: 1153-1161.

King G et al. 2007. A 'politically robust' experimental design for public policy evaluation, with application to the Mexican universal health insurance program. Journal of Policy Analysis and Management 26(3): 479-506.

King G et al. 2009. Public policy for the poor? A randomised assessment of the Mexican universal health insurance programme. The Lancet 373: 1447-1454.

Kremer M et al. 2006. Contracting for health: evidence from Cambodia. Unpublished manuscript, Harvard University. Laver R. 2000. Private Health Care in Latin America: Emerging Opportunities. Institute of the Americas: La Jolla; 1-12.

Magnoni B, Natilson N, Bolaños G. 2005. Estudio de Factibilidad de la Incorporación del Sector Laboral Independiente en el Seguro Facultativo de Salud del INSS. Original Feasibility Study submitted by the Banking on Health Project to the INSS in 28 September 2005.

Matin I, Hulme D, Rutherford S. 2002. Finance for the poor: from microcredit to microfinancial services. Journal of Economic Development 14: 273-294. 
McIntyre D, Thiede M, Dahlgren G, Whitehead M. 2006. What are the economic consequences for households of illness and of paying for health care in low- and middle-income country contexts? Social Science and Medicines 62(4): 858-865.

Miller G, Pinto D, Vera-Hernández M. 2009. Supply- vs. demand-side rationing in developing country health insurance: evidence from Colombia's 'Régimen Subsidiado'. Working Paper.

Morduch J. 1999. Between the state and the market: can informal insurance patch the safety net? The World Bank Research Observer 14: 187-207.

Morduch J, Sharma M. 2002. Strengthening Public Safety Nets from the Bottom Up. The World Bank: Washington, DC.

Narayan D, Chambers R, Shah M, Petesch P. 2000. Voices of the Poor: Crying Out for Change. Oxford University Press: New York.

Panopoulus G, Vélez CE. 2001. Subsidized health insurance, proxy means testing, and the demand for health care among the poor in Colombia. Colombia Poverty Report, vol. 2. World Bank: Washington.

Pauly M, Blavin F, Meghan S. 2008. Is there a market for voluntary health insurance in developing countries? NBER Working Paper \#14095, Cambridge, MA.

Pauly M, Zweifel P, Scheffler R, Preker A, Bassett M. 2006. Private health insurance in developing countries. Health Affairs 25(2): 369-379.

Preker AS, Carrin G, Dror DM, Jakab M, Hsaio W, Arhin D. 2002. Effectiveness of community health financing in meeting the cost of illness. Bulletin of the World Health Organization 80(2): 143-150.

Russell S. 2004. The economic burden of illness for households in developing countries: a review of studies focusing on malaria, tuberculosis, and human immunodeficiency virus/acquired immunodeficiency syndrome. American Journal of Tropical Medicine and Hygiene 71(Suppl. 2): 147-155.

Sekhri N, Savedoff W. 2005. Private health insurance: implications for developing countries. Bulletin of the World Health Organization 83: 127-134.

Smith K, Sulzbach S. 2008. Community-based health insurance and access to maternal health services: evidence from three West African countries. Social Science and Medicines 66(12): 2460-2473.

Thornton R, Moncada MG, Islam M. 2007. Randomized evaluation of a program extending social security health insurance to the informal sector via MFIs in Nicaragua. Baseline Report, Private Sector Partnerships-One Project (Abt Associates Inc.) and Global Development Network, Bethesda, MD.

Wagstaff A. 2007. Health insurance for the poor: initial impacts of Vietnam's health care fund for the poor. Policy Research Paper Series Working Paper $\# 4134$, The World Bank.

Wang H, Yip W, Zhang L, Hsiao W. 2009. The impact of rural mutual health care on health status: evaluation of a social experiment in rural China. Health Economics 18(S2): S65-S82. 